\title{
MONITORING RESIDUES OF AGROCHEMICALS IN COMMERCIAL DRIED HERBS USING GC-MS-SIM
}

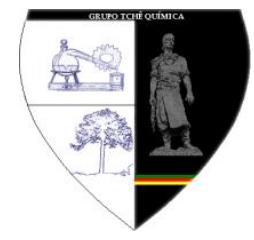

\author{
DE LIMA, Rayani Almeida'; DE MEDEIROS, Giovana Mendonça'; UEKANE, Thais Matsue ${ }^{2}$; \\ DE REZENDE, Claudia Moraes ${ }^{3}$; and ALVES, Andréa Aparecida Ribeiro ${ }^{{ }^{*}}$
}

\begin{abstract}
${ }^{1}$ Instituto de Ciências Exatas, Departamento de Química, Universidade Federal Fluminense, Rua Desembargador Ellis Hermydio Figueira, 783, Aterrado, Volta Redonda - RJ, Brasil, CEP: 27213-145
\end{abstract} (phone +55 243076 8986)

${ }^{2}$ Departamento de Bromatologia, Universidade Federal Fluminense, Rua Mário Viana, 523, Santa Rosa, Niterói - RJ, Brasil, CEP: 24241-002

(phone +55 212629 9592)

${ }^{3}$ Instituto de Química, Universidade Federal do Rio de Janeiro, Avenida Athos da Silveira Ramos, no 149, Bloco A, Centro de Tecnologia, Rio de Janeiro-RJ, Brasil, CEP: 21941-909

(phone +55 213938 7001)

\author{
${ }^{*}$ Autor correspondente \\ e-mail: aaralves@id.uff.br
}

Received 15 April 2018; received in revised form 31 May 2018; accepted 3 june 2018

\section{RESUMO}

As ervas aromáticas secas apresentam muitos compostos químicos precursores de aromas agradáveis, o que justifica seu uso na culinária. No entanto, como qualquer produto agrícola, estão sujeitas a contaminações por resíduos de agrotóxicos. O Codex Alimentarius Internacional é o órgão que regulamenta as normas e limites máximos de resíduos permitidos em uma cultura e, no Brasil, o órgão responsável pela regulamentação é a ANVISA. O objetivo deste trabalho foi desenvolver e validar um método para monitorar resíduos dos agrotóxicos aldrin, dicofol, dieldrin e metidationa em ervas aromáticas secas de manjericão, alecrim, orégano, erva doce, louro e cravo-da-índia utilizando a extração em fase sólida para o cleanup e préconcentração dos agrotóxicos e a GC-MS-SIM. O método foi validado de acordo com os parâmetros de seletividade, linearidade, exatidão, precisão intermediária, limite de detecção e qualtificação. Na exatidão, obtiveram-se valores acima de $90 \%$ para todos os compostos; a precisão intermediária avaliada pelo DPR variou de 2,4 a $3,1 \%$ e os limites de detecção e quantificação dos agrotóxicos ficaram entre 0,21 a $1,65 \mathrm{mg} \mathrm{L}^{-1}$ e 0,62 a $5,00 \mathrm{mg} \mathrm{L}^{-1}$, respectivamente. Estes parâmetros encontraram-se dentro dos valores aceitáveis pela ANVISA. O método proposto foi aplicado em 34 amostras comerciais de ervas aromáticas secas, não sendo detectado ou quantificado resíduos dos agrotóxicos estudados nas mesmas.

Palavras-chave: agroquímicos, ervas secas, GC-MS-SIM, resíduos.

\section{ABSTRACT}

Dried herbs presents several chemical compounds that are precursor of pleasant aroma, which justifies its use in cooking. However, as in every agricultural product, they are subject to have agrochemical residue contamination. International Codex Alimentarius is the responsible for regulation, standardization and establishment of maximum residue limits allowed in each culture, and in Brazil, ANVISA is responsible for this regulation. The aim of this work was to develop and validate a method to monitor the agrochemicals aldrin, dicofol, dieldrin, and methidathion in basil, rosemary, oregano, fennel, bay leaf and clove dried herbs, using solid phase extraction and GC-MS-SIM. The method was validated according to the selectivity, linearity, accuracy, intermediate precision, limit of detection and quantification parameters. Accuracy results were higher than $90 \%$ for all agrochemicals; intermediate precision assessed as RSD, ranged from 2.4 to $3.1 \%$; detection of limit and quantification of limit were between 0.21 to $1.65 \mathrm{mg} \mathrm{L}^{-1}$ and 0.62 to $5.00 \mathrm{mg} \mathrm{L}^{-1}$, respectively. 
Validated parameters were within acceptable values for ANVISA. The developed method was applied to 34 commercial samples of dried herbs, and any of the agrochemicals studied were detected or quantified in these samples.

Keywords: agrochemicals, dried herbs, GC-MS-SIM, residues.

\section{INTRODUCTION}

Dried herbs are plants that contain several chemical compounds, volatile and non-volatile, that release pleasant aromas, giving flavor and odor to foods and are thus widely used in cooking. These herbs are culturally known for their beneficial effects healthy, with reported digestive, anti-inflammatory, antimicrobial, antioxidant and anticancer activities due to the presence of bioactive compounds such as terpenoids and phenolic compounds (Guiné, 2016).

Agricultural products, including dried herbs, are subject to insect attack and disease both in the field and during their storage and, therefore, chemical compounds are generally used for their protection, such as pesticides (Łozowicka et al., 2014), thus avoiding losses of productivity.

According to the Food and Agriculture Organization of the United Nations (FAO), pesticide is any substance or mixture of substances of chemical or biological ingredients intended to repel, destroy or control any pest or regulate the growth of the plant (FAO, 2017a).

The world market for agrochemicals has increased significantly in recent years, reaching a value of around US $\$ 52$ billion in 2013, with a projection of increase to US $\$ 76$ billion by 2019 (Caldas, 2016). In addition, dried herbs market is expanding due to their high demand based on their phytotherapeutic properties and the search for natural options in food. As a result, it is necessary to increase agricultural production, which currently in Brazil is associated with the use of agrochemicals and fertilizers. Despite the agricultural benefits of agrochemicals uses, contamination can occur through the transfer of their residues from plants to animals or humans through bioaccumulation in the food chain, direct contamination during the agricultural activities or through the ingestion of contaminated food (Nantia et al., 2017).

Literature reports that agrochemicals residues can have damaging effects to human health, from short-term impacts such as headaches and nausea to chronic impact that can lead to cancer, reproductive damage and endocrine disorders (Jasim et al., 2017). For this reason, it is very important to monitor levels of these agrochemicals residues found in crops to ensure the safety in consumption of food by the population (Sadowska-Rociek et al., 2013).

In the world, the monitoring of agrochemicals residues in food is based on their maximum residue limits (MRLs), which is the maximum concentration of an agrochemical residue, expressed in $\mathrm{mg} \mathrm{kg}^{-1}$, regulated by the Codex Alimentarius Commission that is legally permitted in food crops (FAO, 2017b) and in Brazil, these values are registered by the monographs of the ANVISA - Agência Nacional de Vigilância Sanitária (ANVISA, 2017).

The gas chromatography coupled to mass spectrometry (with quadrupole analyzer) using selective ion monitoring (GC-MS-SIM) has been applied for agrochemicals residues analysis in food matrices due to its high sensitivity and selectivity, these conditions are essentials for the quantification of trace elements. Cherta et al., (2013) used GC-MS-SIM for the analysis of several agrochemical residues from different classes in fruits and vegetables, such as organophosphates, organochlorines and fungicides. This technique has been reported for organophosphates, organochlorines agrochemicals (Alves et al., 2012) and fungicides (Rodrigues et al., 2017) analysis in citric essential oils and Brazilian whole grape juice (Alves et al., 2014).

Organophosphates agrochemicals (OP), for example methidathion, are compounds soluble in water, which favors their degradation in the environment, their good results in pest and disease control, nevertheless they are classified as moderate toxic according to ANVISA. Therefore, its excessive application is a concern factor once it could generate several risks to human health, even at low levels (Łozowicka et al., 2014; Dou et al., 2015). 
Organochlorines agrochemicals (OC), for example aldrin, dieldrin and dicofol, are known as systemic chemical compounds, that is, they have high persistence in nature, chemical stability and low solubility in water, which have made the OC subject to governmental restrictions and prohibitions since the 1990s. Even today contamination by these OC compounds in several food matrix (Cherta et al., 2013; Alves et al., 2012; Rodrigues et al., 2017; Alves et al., 2014) are observed, since they remain active for years, mainly in the soil, accumulating in the food chain and contaminating the region in which they were applied (Santos et al., 2015). It is important to point out that neither $\mathrm{OP}$ and $\mathrm{OC}$ agrochemicals are allowed in dried herbs crops in the world.

Solid phase extraction (SPE) is very efficient technique to promote cleanup in complex samples, such as those food matrices (Alves \& Barbosa, 2018) as well as for the preconcentration of the analytes of interest.

The aim of this article was to develop and validate a method for residues of aldrin, dieldrin, dicofol and methidathion in basil, rosemary, oregano, fennel, bay leaf and clove dried herbs using solid phase extraction (SPE) and gas chromatography coupled to mass spectrometry with selective ion monitoring (GC-MS-SIM). The proposed method was applied to the analysis of 34 commercial dried herbs.

\section{MATERIALS AND METHODS}

\subsection{Materials}

Six commercial dried herbs (basil, rosemary, oregano, fennel, bay leaf and clove) (Figure 1.) from different brands were acquired in a local supermarket in Volta Redonda City (RJ, Brazil), with a total of 34 samples these were coded presented in Table 1.

Commercial agrochemical standards were from Dr. Mark Ehrenstorfer $\mathrm{GmbH}^{\circledR}$ (Germany) and $n$-eicosane, used as internal standard (IS) was from Sigma-Aldrich ${ }^{\circledR}$, all standards have purity over $99 \%$ (Table 1 ).

Solid phase extraction (SPE) was performed with a Florisil stationary phase cartridge (Waters Mark, $2 \mathrm{~mL}$, Sep-Pak, code 227932341A). Pure for analysis acetone
(Dynamics, Brazil - lot 79418) was used for cartridge conditioning, for elution hexane (Dynamics, Brazil - lot 81160) and ethyl acetate (Dynamics, Brazil - lot 80580) were used.

\subsection{Instrumentation and Operating Conditions for GC-MS-SIM}

The Agilent Technologies $^{\circledR}$ (Califórnia, EUA) GC (Model 7820A) coupled with a 5977E mass detector (with quadrupole analyzer) and a 7683B Automatic Liquid Sampler was used in the research work.

The GC separation was carried out on a DB5-MS (Agilent 122-S002) column with $30 \mathrm{~m}$ length, $0.25 \mathrm{~mm}$ I.D., and film thickness $0.25 \mu \mathrm{m}$ from Agilent Technologies ${ }^{\circledR}$ (Califórnia, EUA) with an injection volume of $1 \mu \mathrm{L}$.

The oven temperature gradient was started at $100^{\circ} \mathrm{C}$ and held for $1 \mathrm{~min}$. Then it was raised to $180{ }^{\circ} \mathrm{C}$ at the rate of $20{ }^{\circ} \mathrm{C} \mathrm{min}^{-1}$, followed by an increase rate of $3^{\circ} \mathrm{C} \mathrm{min}^{-1}$ to 220 ${ }^{\circ} \mathrm{C}$ and an increase rate of $20^{\circ} \mathrm{C} \min ^{-1}$ to $310^{\circ} \mathrm{C}$, with a total run time of 20.7 minutes.

Helium, 5.0 analytical grade, was used as a carrier gas with a constant flow rate of $0.8 \mathrm{~mL}$ $\min ^{-1}$ with split mode 1:50. The injector temperature, transfer line, ion source and the quadrupole analyzer were kept at $270{ }^{\circ} \mathrm{C}, 290$ ${ }^{\circ} \mathrm{C}, 230^{\circ} \mathrm{C}$ and $150^{\circ} \mathrm{C}$, respectively.

The mass spectrometry in electron impact (EI) mode at $70 \mathrm{eV}$ was utilized for sample ionization with a solvent delay of 4.0 minutes. The GC-MS spectra for agrochemicals and internal standards were obtained through the injection of the solutions and scanning in the range of $\mathrm{m} / \mathrm{z} 50-700$. Standard solutions mass spectra were compared with the NIST 14 library from the GC-MS solution software. Three diagnostic ions were selected for each compound for the creation of the selective ion monitoring method (SIM) for validation and analysis of real samples.

\subsection{Preparation of agrochemicals and internal standard stock solution}

The standard solutions of agrochemicals and the internal standard (IS) (Table 1) were prepared in concentrations by weighing in an analytical balance (Bioscale model no. 2204, N / S 20140148, with four decimal places) $10.0 \mathrm{mg}$ of 
each the standard separetly, adding hexane to the volume of $10.0 \mathrm{~mL}$ to obtain a final concentration of $1.0 \mathrm{mg} \mathrm{mL}^{-1}$ each.

\subsection{Multielemental solution}

From the stock standard solutions a multicomponent solution containing the agrochemicals and the IS, named working solution was prepared. An aliquot of $100 \mu \mathrm{L}$ from each standard solution was withdrawn and placed in a vial, where hexane was added to make up to 1.0 $\mathrm{mL}$, which resulted in a solution with a concentration of $100 \mathrm{\mu g} \mathrm{mL}^{-1}$ of each standard.

\subsection{Sample preparation}

Dried herbs extract were prepared from the maceration and/or cutting of $5 \mathrm{~g}$ of each herb, weighted in an analytical balance (DIAMOND MODEL A04 $500 \mathrm{~g} / 0.1 \mathrm{~g}$ ) and then extracted with $10 \mathrm{~mL}$ of hexane (Figure 2.). The hexane solution was allowed to stand for 1 hour in a closed flask and, after filtrated to remove the plant material, and then the solvent was completely dried under vacuum. To this dried extract, $3 \mathrm{~mL}$ of hexane was added to obtain the final extract of the dried herb.

\subsection{SPE analysis of dried herbs extract}

For the SPE extraction of samples, Florisil stationary phase EFS cartridges $(2 \mathrm{~mL}$ ) (Figure 3.) were conditioned with $1 \mathrm{~mL}$ of acetone. Hexane extract $(2 \mathrm{~mL})$ of the dried herb, prepared as described above, was passed through the SPE cartridge, after $1.5 \mathrm{~mL}$ of ethyl acetate and $1.5 \mathrm{~mL}$ of hexane were eluted in the cartridge and collected in a single fraction. The eluted solvents were completely dried under nitrogen then $2 \mathrm{~mL}$ of hexane was added and the extract was stored under refrigerator. The elution occurred by positive gravity, without automation or vacuum application.

\subsection{Method validation}

For method validation, the basil sample was used, that had been previously checked for the absence of the agrochemicals of interest (blank). This basil sample was chosen once it had fewer peaks of compounds in the retention time regions of the investigated analytes, assessed through the agrochemicals retention times used in this research. From this blank sample extract, the analytical parameters of selectivity, linearity, accuracy, intermediate precision and limits of detection (LD) and quantification (LQ) were evaluated.

Linear working range used for the construction of analytical curves was between 1 and $25 \mathrm{mg} \mathrm{L}^{-1}$. The analytical curves were built from five different concentrations of the agrochemicals standards $(1,5,10,15$ e $25 \mathrm{mg} \mathrm{L}$ $\left.{ }^{1}\right)$, analyzed in triplicate and internal standard concentration was fixed concentration of $10 \mathrm{mg} \mathrm{L}$ 1 . The linearity was evaluated by measuring the area ratio for each analyte to the IS over the range of the analytical curve and the obtained data were subjected to statistical analysis using a linear regression model. ANVISA recommends five levels of concentration and replicates of at least three to obtain good linearity assessment with low relative standard deviation (RSD) (Ribani et al., 2004).

Limits of detection (LD) and quantification (LQ) values were obtained from linear regression equations for each agrochemical according to the equations: $L D=3.3 \times(\mathrm{s} / \mathrm{S})$ and $L Q=10 \times(\mathrm{s} / \mathrm{S})$. Where, the $s$ e $S$ values were correspondent to the linear coefficient and the slope of the analytical curves, respectively (Ribani et al. 2004).

Intermediate precision, assessed by repeatability experiments was calculated by the relative standard deviation (RSD), expressed by the equation: $\operatorname{RSD}(\%)=\left(s / X_{m}\right) \times 100$. Where $s$ is the absolute standard deviation, $X_{m}$ is the mean area ratios of the agrochemical and IS, obtained from the five concentrations analysis, in triplicate, of the analytical curve.

Accuracy, assessed by recovery, was calculated by spiking known amounts of agrochemicals standards in the blank extract. Agrochemical concentration values from the analytical curves plotted, as for linearity experiments, were calculated and from these values the percentage of recovery was assessed, as the difference between the amount spiked of each standard to the sample and the calculated value obtained by the analytical curves.

\section{RESULTS AND DISCUSSION}

For the method validation, blank extracts of basil dried herb were used, whose time region between 12 to 18 minutes, where the 
agrochemicals standards studied eluted (Figure 4. magnified window), no compounds from the dried herb matrix could be detected that could interfere with these compounds analysis.

From the GC-MS scan spectra for agrochemicals and internal standards $(\mathrm{m} / \mathrm{z} 50$ 700 ), it was possible to assess retention times from each standard and to select the three characteristics ions, presented in Table 2.

The linearity was evaluated by the analytical curve using a linear regression model and results of this regression and correlation coefficient $(R)$ are presented in Table 3 . The analytical curves were constructed from the ratio between the agrochemicals and the internal standard areas, using Microsoft Excel ${ }^{\circledR}$ software.

Correlation coefficient (R) were higher than 0.990 for all agrochemicals studies and these values were considered with good fit to the linear regression model applied, according to ANVISA and INMETRO acceptance levels of 0.990 and 0.900 , respectively (Ribani et al., 2004).

The method for LD and LQ calculation based on the analytical curves parameters was chosen once it was statistically more reliable (Ribani et al., 2004), which results are presented in Table III. $L D$ and $L Q$ values ranged from 0.21 to $1.65 \mathrm{mg} \mathrm{L}^{-1}$ and 0.62 to $5.00 \mathrm{mg} \mathrm{L}^{-1}$. These parameters are important for method development and validation once they can suggest compliance from legal limits established of any compound (Ribani et al., 2004). However, for the agrochemicals studied in this article Codex Alimentarius Internacional (FAO, 2017b) and ANVISA (2017) do not established values of MRLs for dried herbs. Thus, the values found for LD and LQ were considered satisfactory.

To evaluate the intermediate precision and recovery of the method, the RSD \% and recovery were calculated, respectively and the results are shown in Table 4.

ANVISA establishes that RSD values for intermediate precision should be less than $5 \%$ (Ribani et al., 2004) and recovery values should be between 70 and $120 \%$. All RSD \% values were below $3.1 \%$ in the validated method and recoveries were higher than $90.6 \%$ for all the agrochemicals compounds, thus the values obtained were considered satisfactory. Based on these informations, the validation method proposed presented good precision and accuracy.

Comparing the present validated method with other works described in the literature, it is observed that the analytical parameters were in agreement. Nguyen et al. (2010) validated a method for the determination of agrochemicals in two types of Korean dried herbs using GC-MS, whose recovery values of aldrin, dicofol and dieldrin ranged from 78 to $102 \%$. SłowikBorowiec (2015) analyzed agrochemicals residues in mint and obtained recovered values of $84 \%$ and $92 \%$ for aldrin and dieldrin, respectively, with $6 \%$ repeatability for both compounds.

For the final phase of this research, the validated method was applied to 34 commercial dried herbs samples to verify and monitor residues of the agrochemicals studied. As a result of this analysis it was observed that no agrochemical residue was detected or quantified in these samples, if these agrochemicals residues were present, they were with values below the LD and LQ of the validated method.

Hou et al. (2016) analyzed agrochemicals residues of different classes (pyrethroids, organochlorines, organophosphates, among others) in 20 samples of dried green tealeaves using GC, and also did not quantify residues of within their samples. In a similar study, Pareja et al. (2015) obtained similar results in the analysis of multiresidue agrochemicals where they analyzed 9 real samples of dried leaves of yerba mate (Ilex paraguaiensis). Sadowska-Rociek et al. (2013) detected dieldrin in fresh herbs of rosemary, oregano and basil, but also did not quantify these residues in the samples.

In Brazil, nowadays, there is no law that defines the levels of agrochemicals residues in dried herbs, there is only regulation concerning the definition of herbs, condiments and spices, their different classifications and how the preparation of tea and others from these herbs should be. Therefore, this work could help the government authorities to elaborate a possible standardization regarding the residues of agrochemicals in dried herbs, since these are continuously consumed by the population and so should be monitored. In view of the results obtained from this study, one can consider a positive point for the sanitary and health issue of 
the country, since no agrochemical residues were quantified in the commercial samples studies.

\section{CONCLUSIONS}

In this article, a method was developed and validated for the analysis of agrochemicals residues in dried herbs using SPE and GC-MSSIM. The results obtained through the validation parameters indicated that the SPE proved to be efficient in the extraction and pre concentration of these residues and GC-MS-SIM a good technique for this investigation, since it allowed sensitivity and selectivity of the agrochemicals chosen for study. The analytical parameters were within the values established by ANVISA, thus giving credibility to the validated method.

The validated method was applied to 34 commercial samples of dried herbs of rosemary, basil, fennel, bay leaf and clove, and no agrochemicals residue were detected or quantified in these samples, which was positive for sanitary purposes and country health. However, since there are no law governing agrochemicals residues in this type of sample, it is important that there be further monitoring, given the wide use of herbs by the population, so it is expected that this work will contribute to this end.

\section{ACKNOWLEDGMENTS}

The authors are grateful to the Universidade Federal Fluminense (UFF), the Universidade Federal do Rio de Janeiro (UFRJ) and the Fundação Carlos Chagas Filho de Amparo à Pesquisa do Estado do Rio de Janeiro (FAPERJ) for research support (APQ1).

\section{REFERENCES}

1. Alves, A.A.R.; Barbosa, E.S. Period. Tchê Quim. 2018, 15, 29, 82.

2. Alves, A.A.R.; Rodrigues, A.S.; Barros, E.B.P.; Uekane, T.M.; Bizzo, H.R.; Rezende C.M. 2014. Food Anal. Method, 2014, 7, 1834.

3. Alves, A.A.R.; Rezende, M.J.C.; Hovell, A.M.C.; Bizzo, H.R.; Oliveira, A.C.L.; Rodrigues, S.V.; Rezende, C.M. J. Braz. Chem. Soc., 2012, 23, 306.
4. ANVISA (Agência Nacional de Vigilância Sanitária). Agrotóxicos. 2017.

http://portal.anvisa.gov.br/registros-eautorizacoes/agrotoxicos/produtos/monog rafia-de-agrotoxicos/autorizadas Accessed April 2018.

5. Caldas, E.D. Pesticide Poisoning in Brazil. 2016. Ed. Elsevier.

https://www.researchgate.net/publication/ 308013830_Pesticide_Poisoning_in_Brazi I Acessed April 2018.

6. Cherta, L., Beltran, J, López F, Hernández F. Food Anal. Method. 2013, 6, 4, 1170.

7. Dou X, Chu X, Kong W, Luo J, Yang M. Anal. Chim. Acta. 2015, 891, 291.

8. FAO (Food and Agriculture Organization of the United Nations). Codex Pesticides Residues in Food Online Database. 2017a, http://www.fao.org/fao-whocodexalimentarius/codex-

texts/dbs/pestres/en/ Accessed April 2018.

9. FAO (Food and Agriculture Organization of the United Nations). Commodities and Development Report 2017. 2017b, http://www.fao.org/3/a-i7937e.pdf Acessed April 2018.

10. Guiné, R.P.F.; Gonçalves, F.J. Mini. Rev. Med. Chem. 2016, 16, 11, 855.

11. Hou X, Lei S, Guo L, Quu S. Braz. J. Pharmacogn. 2016, 26, 4, 401.

12. Jasim, H.H.; Dikran, S.B.; Mahdi, A.S.; Altahir, B.M. Br. J. Anal. Chem. 2017, 4, 14, 25.

13. Łozowicka, B.; Jankowska, M.; Rutkowska, E.; Hrynko, I.; Kaczyński, P.; Miciński, J. J. Nat. Med. 2014. 68, 1, 95.

14. Nantia, E.A.; Moreno-González, D.; Manfo, F.P., Gámiz-Gracia, L.; GarcíaCampaña, A.M. Food Chem. 2017, 216, 334.

15. Nguyen, T.D.; Lee, K.J.; Lee, M.H.; Lee, G.H. Microchem. J. 2010, 95, 1, 43. 
16. Pareja, L.; Niell, S.; Vryzas, Z.; González, J.; Cesio, M.V.; Mourkidou, E.P.; Heinzen, H. Braz. J. Pharmacogn. 2015, 25, 2, 98.

17. Ribani, M.; Bottoli, C.B.G.; Collins, C.H.; Jardim, I.C.S.F. Quím. Nova. 2004, 27, 5 771.

18. Rodrigues, A.S.; Barbosa, E.S., Alves, A,A,R. Rev. Analytica. 2017, 15, 87, 10.

19. Sadowska-Rociek, A.; Surma, M.; Cieślik, E. Bull. Environ. Contam.Toxicol. 2013, 90, 4, 508.

20. Santos, J.S.; Schwanz, T.G.; Coelho, A.N.; Heck-Marques, M.C.; Mexia, M.M.; Emanuelli, T.; Costabeber, I. Food Control. 2015, 53, 23.

21. Slowik-Borowiec, M. Food Anal. Method. 2015, 8, 6, 1413. 


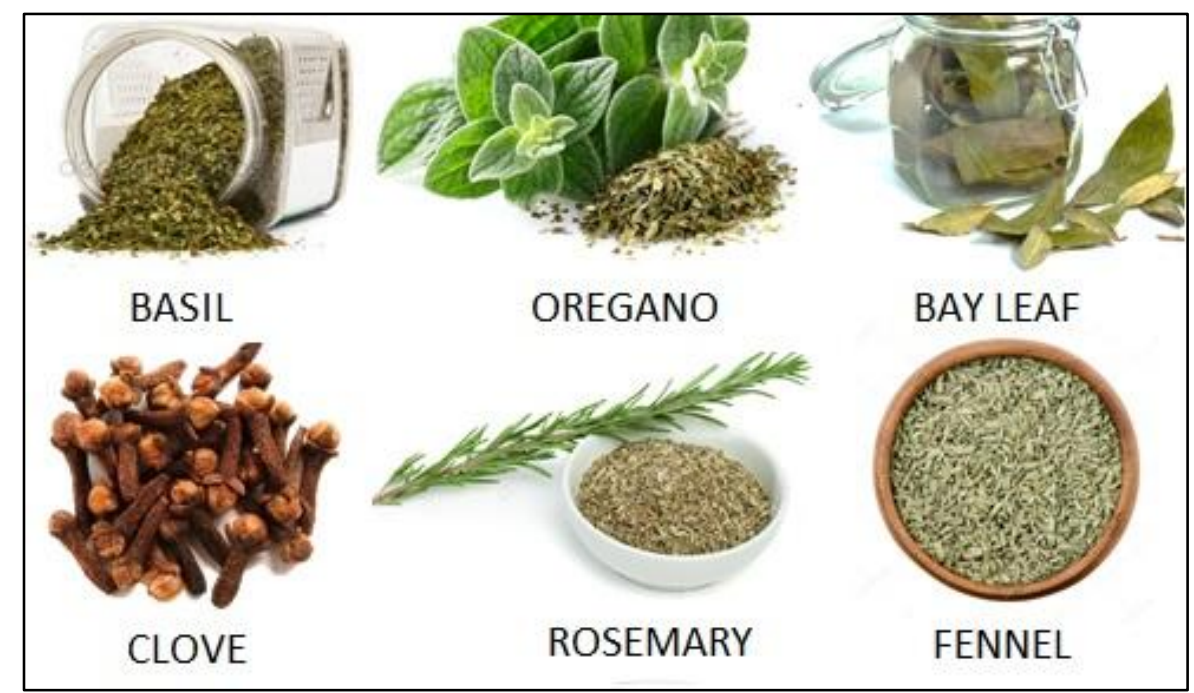

Figure 1. Six commercial dried herbs used in this work: basil, oregano, bay leaf, clove, rosemary and fennel.

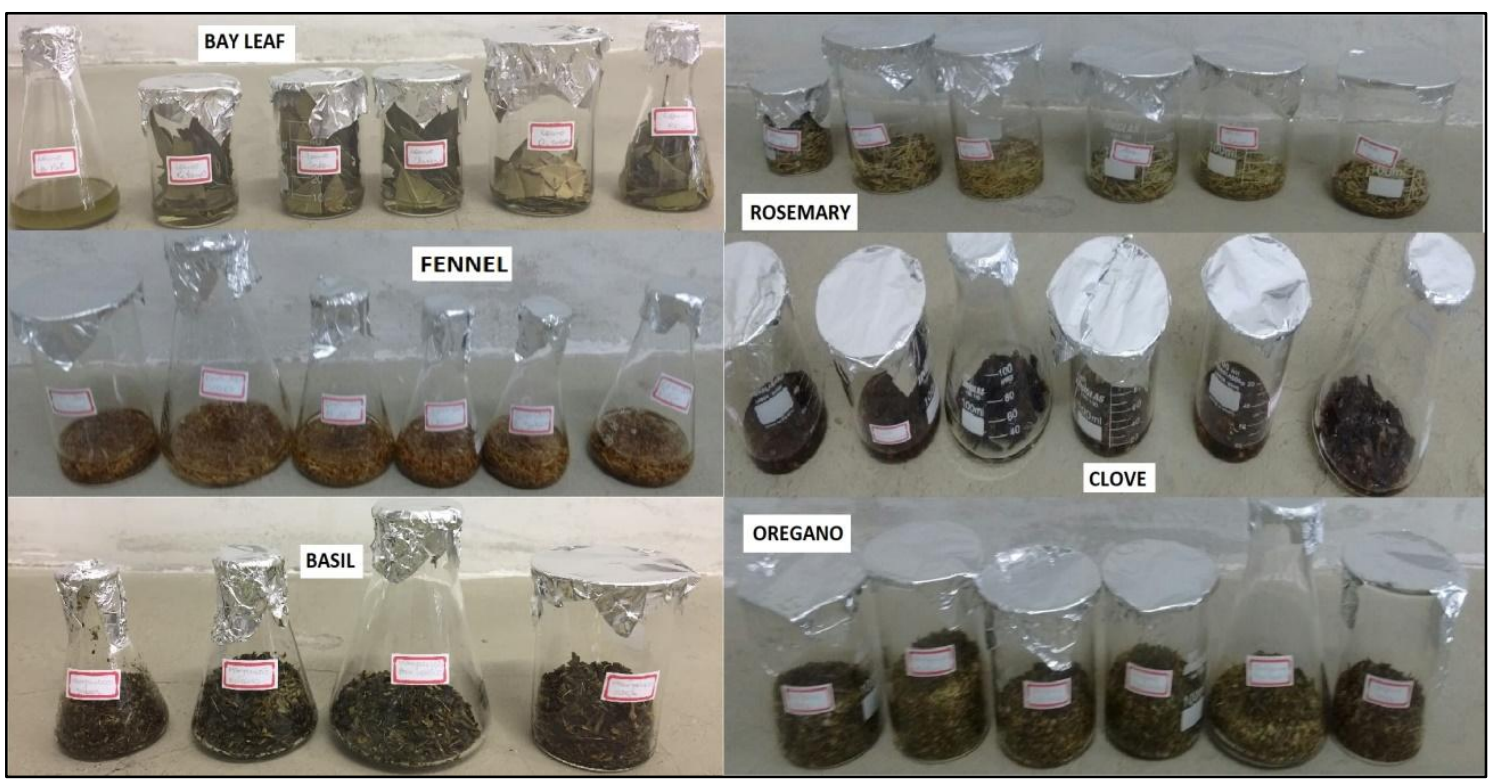

Figure 2. Extracts, in hexane, of dried herbs, previously weighed, macerated and/or cut. 


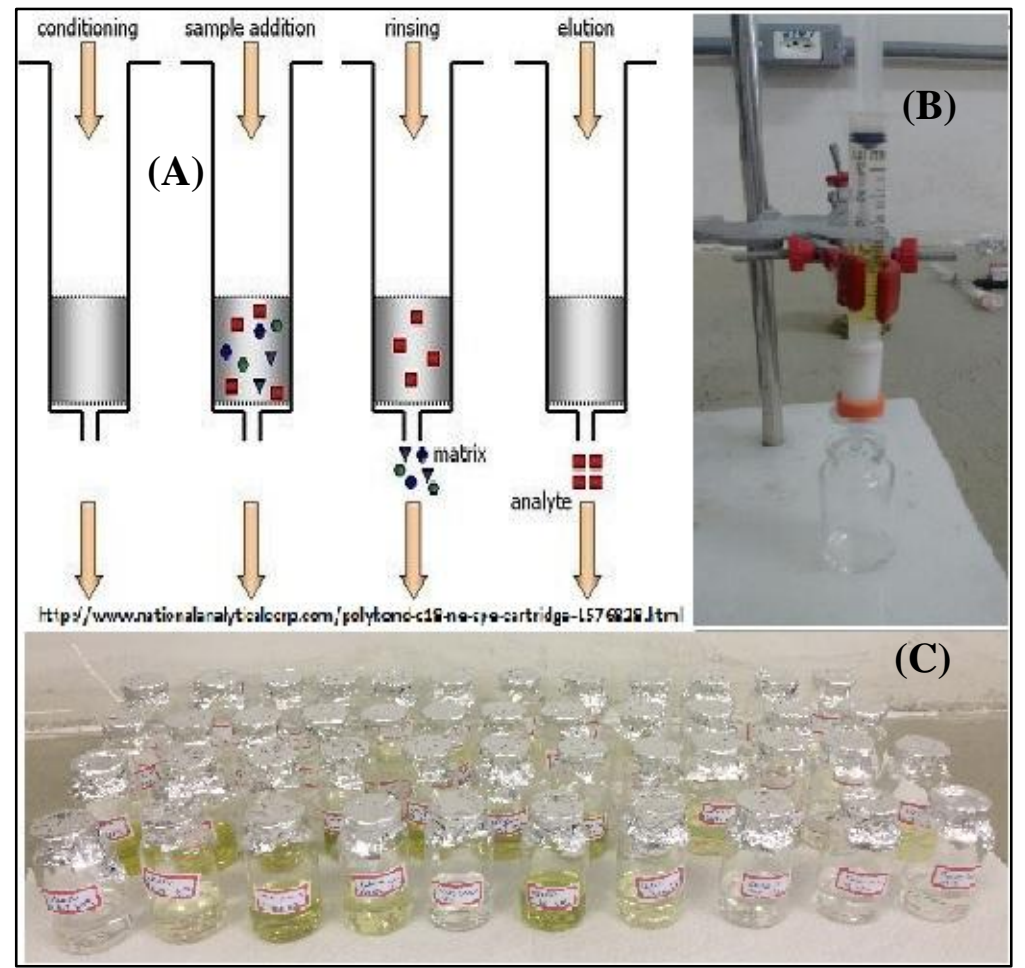

Figure 3. SPE extraction: $(A)$ steps, $(B)$ extraction of a basil sample and (C) samples after extraction

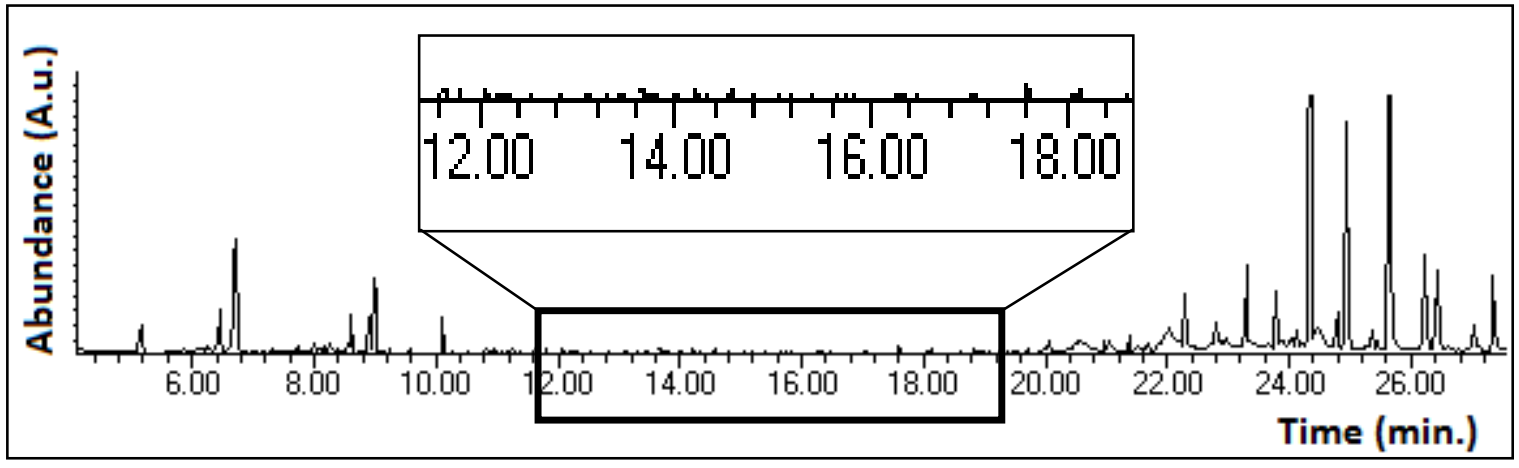

Figure 4. Blank chromatogram of basil sample extract obtained from GC-MS analysis in scan mode; magnified time window 12 to 18 minutes 
Table 1. Dried herbs samples and standard information's used in the present study

\begin{tabular}{ccc}
\hline Dried herbs & Code (commercial brands) & Scientific names \\
\hline Rosemary & BAP, CHI, DSA, KIT, ROC, SAB & Rosmarinus officinalis L. \\
Oregano & BAP, CHI, DSA, KIT, ROC, SAB & Origanum vulgare \\
Fennel & BAP, CHI, DSA, KIT, ROC, SAB & Pimpinela anisum \\
Clove & BAP, CHI, DSA, KIT, ROC, SAB & Caryophilus aromaticus \\
Bay leaf & BAP, CHI, DSA, KIT, ROC, SAB & Laurus nobilis \\
Basil & BAP, KIT, ROC, SAB & Ocimun basilicum L.
\end{tabular}

\begin{tabular}{|c|c|}
\hline Agrochemical & IUPAC* \\
\hline Aldrin & $\begin{array}{l}\text { 1,2,3,4,10,10-Hexachloro-1,4,4a,5,8,8a-hexahydro-1,4:5,8- } \\
\text { imethanonaphthalene }\end{array}$ \\
\hline & 1aR,2R,2aS,3S,6R,6aR,7S,7aS)-3,4,5,6,9,9-hexachloro- \\
\hline Dieldrin & $\begin{array}{c}\text { 1a,2,2a,3,6,6a,7,7a-octahydro-2,7:3,6-dimethanonaphtho[2,3- } \\
\text { b]oxirene }\end{array}$ \\
\hline Dicofol & 2,2,2-trichloro-1,1-bis(4-chlorophenyl)ethanol \\
\hline Methidathion & $\begin{array}{l}\text { S-2,3-dihydro-5-methoxy-2-oxo-1,3,4-thiadiazol-3-ylmethyl O,O- } \\
\text { dimethyl phosphorodithioate }\end{array}$ \\
\hline $\begin{array}{l}\text { Internal } \\
\text { standard }\end{array}$ & n-eicosane \\
\hline
\end{tabular}

Table 2. Retention times and characteristics ions for each agrochemical standard using GC-MS-SIM

\begin{tabular}{ccc}
\hline Compound & $\mathbf{R}_{\mathbf{t}}(\mathbf{m i n})$. & Characteristic ions $(\mathbf{m} / \mathbf{z})$ \\
\hline Organochlorine (OC) & & \\
Aldrin & 12.643 & $263,265,293$ \\
Dicofol & 12.963 & $139,141,250$ \\
Dieldrin & 16.846 & $237,263,345$ \\
\hline $\begin{array}{c}\text { Organophosphorus (OP) } \\
\text { Methidathion }\end{array}$ & 15.279 & $85,145,302$ \\
\hline Internal Standard (IS) & & \\
$n$-Eicosane & 12.821 & $57,99,324$ \\
\hline
\end{tabular}


Table 3. Linear regression analytical curves, correlation coefficient $(R)$, limit of detection $(L D)$ and quantification $(L Q)$ results for each agrochemical standard from GGMS-SIM method validated

\begin{tabular}{ccccc}
\hline Compound & $\mathbf{R}$ & Equation & $\mathbf{L D}\left(\mathbf{m g ~ L}^{-1}\right)$ & LQ $\left(\mathbf{m g ~ L}^{-1}\right)$ \\
\hline Organochlorine (OC) & & & & \\
Aldrin & 0.993 & $\mathrm{y}=5.664 \mathrm{x}+1.426$ & 1.65 & 5.00 \\
Dicofol & 0.994 & $\mathrm{y}=3.542 \mathrm{x}+0.567$ & 1.24 & 3.75 \\
Dieldrin & 0.994 & $\mathrm{y}=3.273 \mathrm{x}+0.523$ & 1.32 & 4.00 \\
\hline Organophosphorus (OP) & & & & \multirow{2}{*}{0.21} \\
Methidathion & 0.990 & $\mathrm{y}=3.770 \mathrm{x}+0.019$ & 0.21 & \\
\hline
\end{tabular}

Table 4. Intermediate precision and accuracy values calculated for each agrochemical standard from GC-MS-SIM method validated.

\begin{tabular}{ccc}
\hline Compound & RSD (\%) & Recovery (\%) \\
\hline Aldrin & 2.8 & 91.9 \\
Dicofol & 2.4 & 90.8 \\
Dieldrin & 2.5 & 90.6 \\
Methidathion & 3.1 & 90.8 \\
\hline
\end{tabular}

PERIÓDICO TCHÊ QUÍMICA • www.periodico.tchequimica.com • Vol. 16 N. 31

- ISSN 1806-0374 (impresso) • ISSN 1806-9827 (CD-ROM) • ISSN 2179-0302 (meio eletrônico) 